L. Walling

\title{
Impedance Measurements of the LEB Extraction Kicker Magnet
}

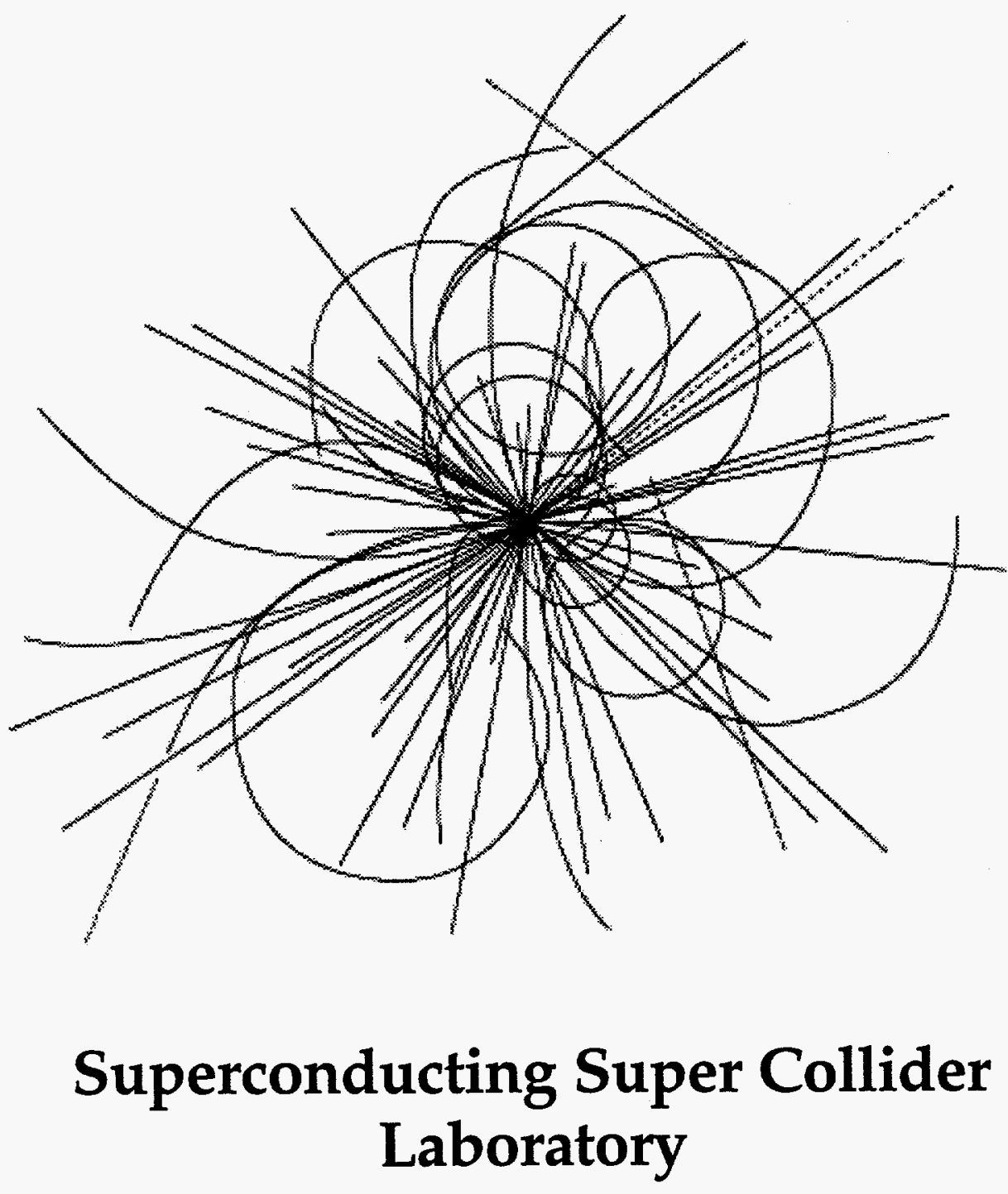

RECEIVED NoV 021994 OSTI

\section{Laboratory}




\section{Disclaimer Notice}

This report was prepared as an account of work sponsored by an agency of the United States Government. Neither the United States Government or any agency thereof, nor any of their employees, makes any warranty, express or implied, or assumes any legal liability or responsibility for the accuracy, completeness, or usefulness of any information, apparatus, product, or process disclosed, or represents that its use would not infringe privately owned rights. Reference herein to any specific commercial product, process, or service by trade neme, trademark, manufacturer, or otherwise, does not necessarily constitute or imply its endorsement, recommendation, or favoring by the United States Government or any agency thereof. The views and opinions of authors expressed herein do not necessarily state or reflect those of the United States Govermment or any agency thereot. 


\section{DISCLAIMER}

Portions of this document may be illegible in electronic image products. Images are produced from the best available original document. 


\title{
Impedance Measurements of the LEB Extraction Kicker Magnet
}

\author{
L. Walling \\ Superconducting Super Collider Laboratory* \\ 2275 North Highway 77 \\ Waxahachie, TX 75165
}

October 1994

"Operated by the Universities Research Association, Inc., for the U.S. Department of Energy under Contract No. DE-AC35-89ER40486. 


\subsection{INTRODUCTION}

This report provides results of longitudinal and transverse impedance measurements of the Low Energy Booster (LEB) Extraction Kicker Magnet of the Superconducting Super Collider (SSC). The kicker magnet was designed to steer the beam upon extraction from the LEB into the septum magnets, requiring a vertical angular deflection of $1.5 \mathrm{mrad}$. This magnet would have been required to generate an integrated field of $0.06 \mathrm{~T}-\mathrm{m}$ for $2 \mu \mathrm{s}$, rising from $1 \%$ to $99 \%$ of peak in $\leq 80 \mathrm{~ns}$. This magnet is described in detail in Reference 1 . Figure 1 shows a cutaway view of the magnet, which is enclosed in a large tank approximately $1 \mathrm{~m}$ in length.

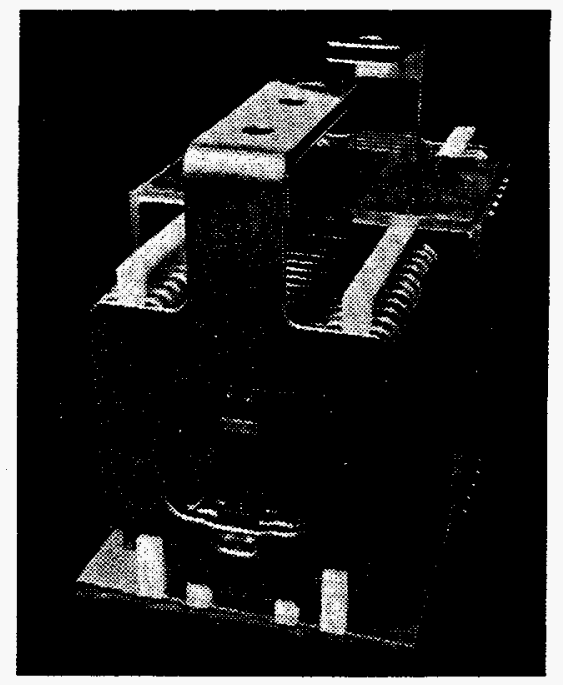

Figure 1. Cutaway view of the 28-cell LEB extraction traveling wave (TW) kicker magnet.

\subsection{MEASUREMENT METHOD}

The wire measurement method $2-4$ was used to perform the measurements. The accuracy of these measurements is approximately $20-40 \%$. The beam pipe diameter was $7.9 \mathrm{~cm}$ and the wire diameter $0.32 \mathrm{~cm}$, and for the transverse measurement the distance between the two wires was $2.0 \mathrm{~cm}$. This resulted in a line impedance of $193 \Omega$ for the longitudinal and $290 \Omega$ for the transverse measurement. Because of the extremely high inductance of this kicker, it was necessary to modify the analysis software in two ways. One was to include more terms in the expansion of the distributed impedance model, and the other was to keep track of non-resonant phase transitions in $S_{21}$ from -180 to +180 and subtract $2 * \pi$ for each. Since it was necessary to break the measurements up into multiple runs with fairly narrow frequency ranges in order to have high enough resolution to calculate the impedances at resonances, it was then necessary to keep track of the cumulative phase from one frequency range set to the next and to correct the phase of the first point of each data run. The reactance is calculated from the phase as follows (see Eq. (11) in Reference 1): 


$$
\begin{gathered}
\phi=-\frac{\omega l}{c}\left[\sqrt{1+\frac{c x}{\omega Z_{c}}}-1\right] \\
\operatorname{Im} Z=l X=\frac{\omega l Z_{c}}{c}\left\{\left[1-\frac{c \phi}{\omega l}\right]^{2}-1\right\} .
\end{gathered}
$$

The resistive part of the impedance is then found (also from Eq. (11) in Reference 1):

$$
\begin{gathered}
\left|S_{21}\right|=e^{-\alpha} \\
\alpha=-\frac{l}{2 Z_{c}}\left[\frac{R+R_{0}}{1+\left(c x / \omega Z_{c}\right)}-R_{0}\right]=\ln \left|S_{21}\right| .
\end{gathered}
$$

Thus,

$$
\operatorname{Re}(Z)=l R=\left(-2 l Z_{c} \ln \left|S_{21}\right|\right)\left(1+\frac{c x}{\omega Z_{c}}\right)
$$

Prior to performing the wire measurements, transmission through the cavity was measured by inserting antennas at both ends of the tank gap. This was necessary to determine the measurement frequency range and to provide insight into the validity of the final impedance measurements.

\subsection{MEASUREMENT RESULTS}

The preliminary measurements that were performed with antennas and no wires are shown in Figures 2 and 3. These show three major resonances: at 30,88 , and $485 \mathrm{MHz}$. This is useful for helping to determine the validity of the wire measurements, because if large resonances at frequencies other than these were to appear in the final results, this would imply that the presence of the wires was creating spurious resonances due to reflections from, say, the magnet end gaps, and would lend doubts as to the validity of the measurements in general. Happily, this did not occur, and these preliminary measurements lend credibility to the final wire measurement results.

The results of the longitudinal impedance measurements are shown in Figures 4-15, and the transverse impedance results are shown in Figures 16-19.

\subsection{CONCLUSIONS}

When these results are compared to the impedance budget of the Medium Energy Booster (MEB) for the SSC, both the longitudinal and transverse impedances of one kicker magnet exceed the calculated total kicker magnet budgets (15 magnets) by approximately one order of magnitude. Comparing to the budget for the LEB, one magnet's longitudinal impedance exceeds the calculated total kicker magnet budget ( 8 magnets) by approximately three orders of magnitude, and the transverse by one order of magnitude. Since the measurement value was for only one magnet, the total discrepancies are an additional order of magnitude larger than stated. Because of these large discrepancies, were the SSC to be built it would be necessary to calculate the magnet impedances using MAFIA in order to confirm (or hopefully, discredit) the measurement results. 


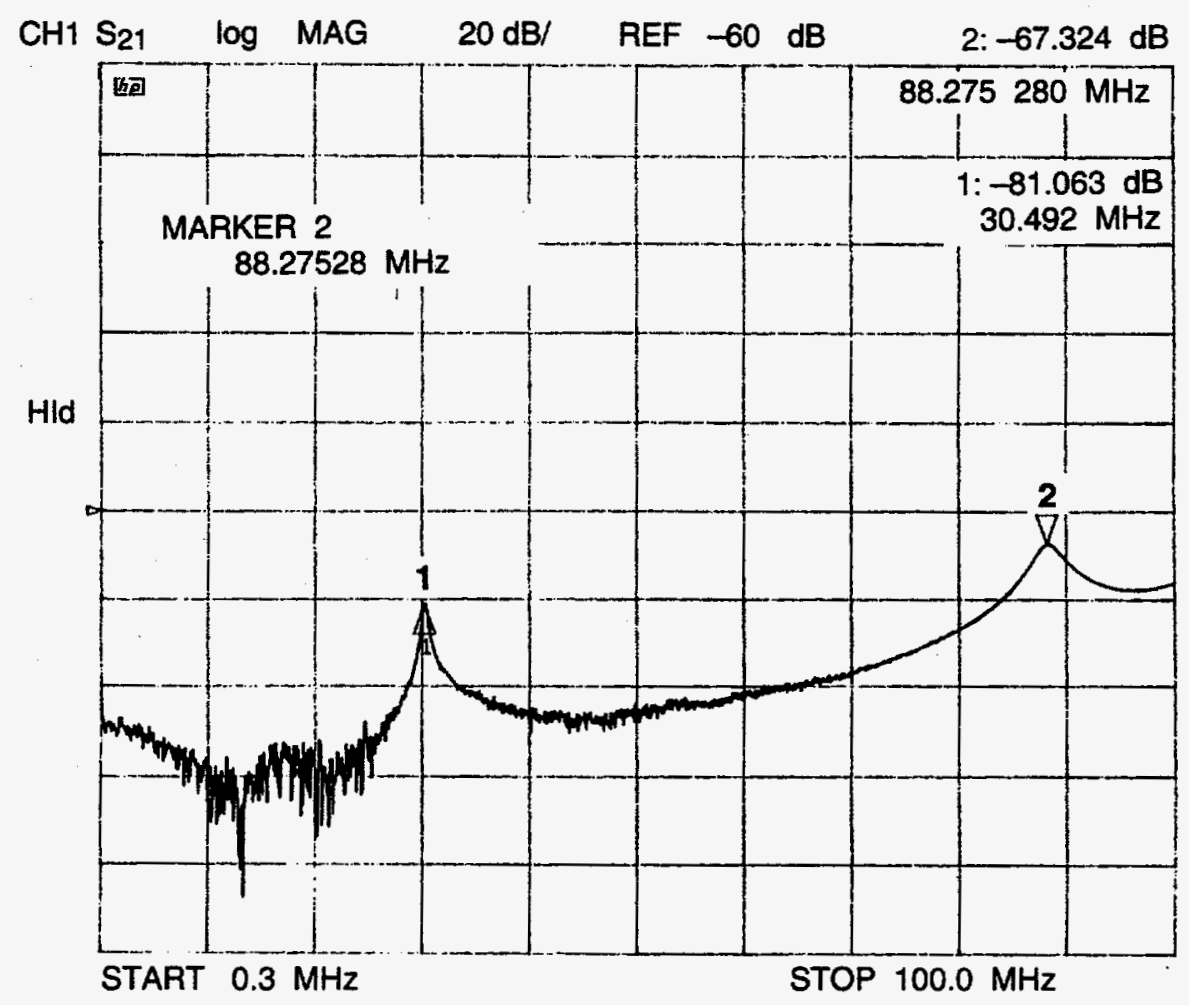

Figure 2. Transmission measurements of klcker magnet using antenna excltation and plckup. 


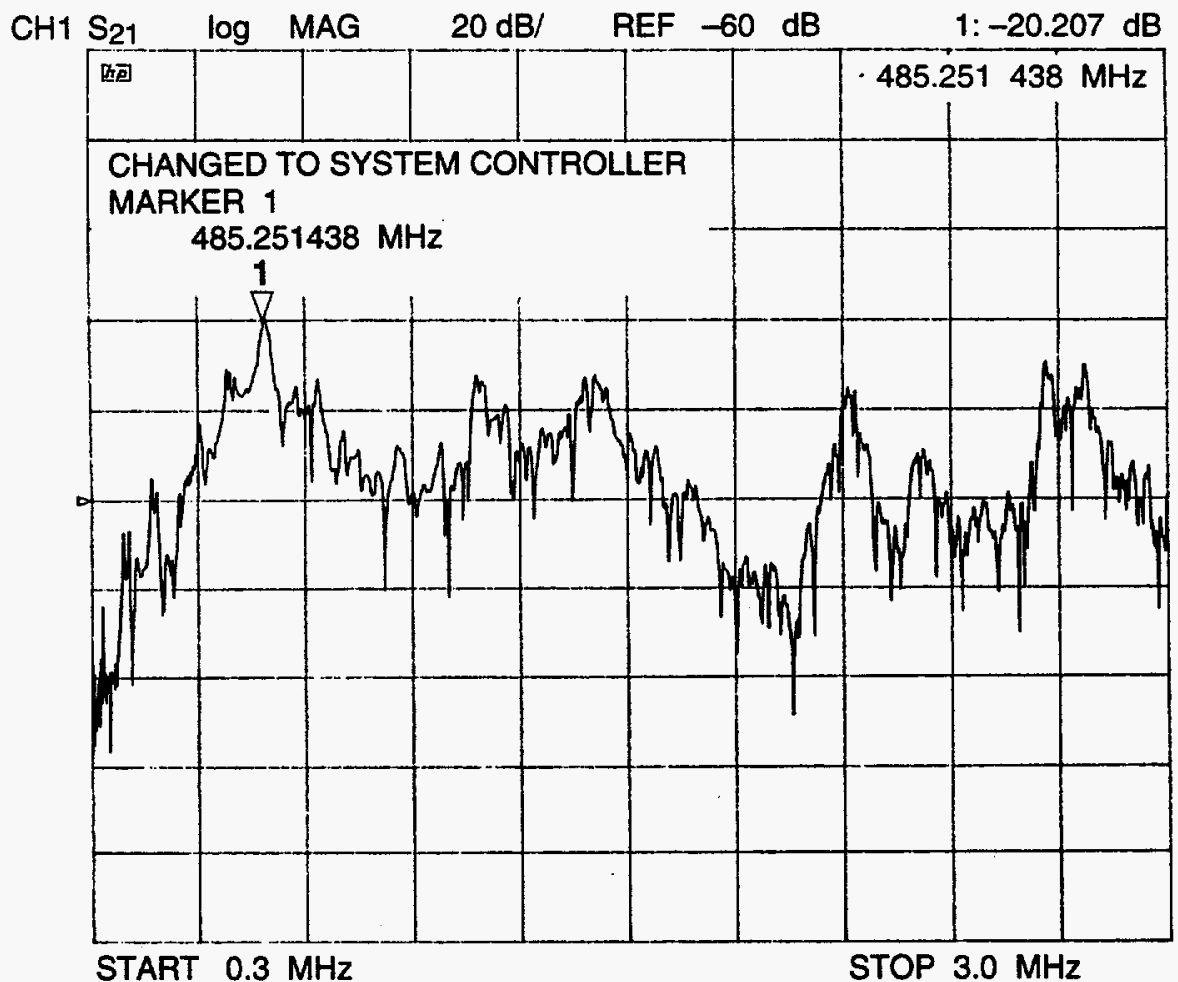

Figure 3. Transmission measurements of kicker magnet using antenna excitation and pickup.

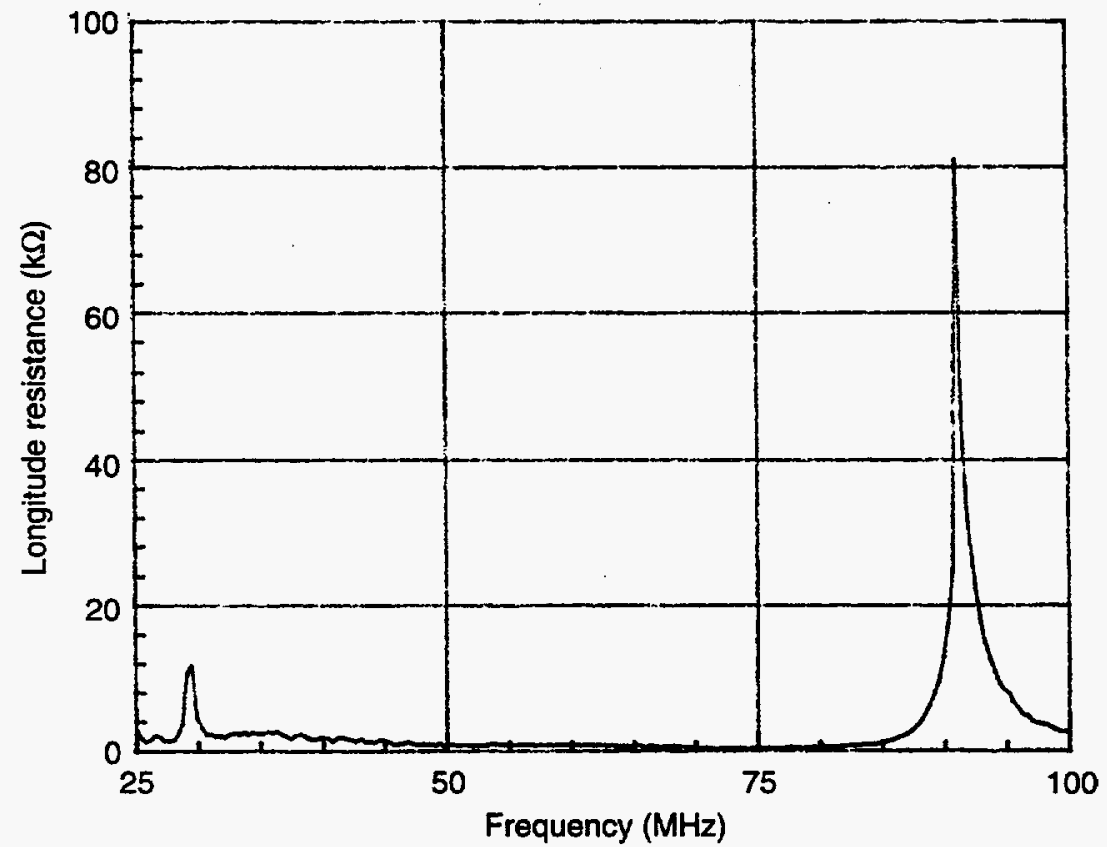

Figure 4. Klcker magnet longltudinal resistive Impedance, 25-100 MHz. 


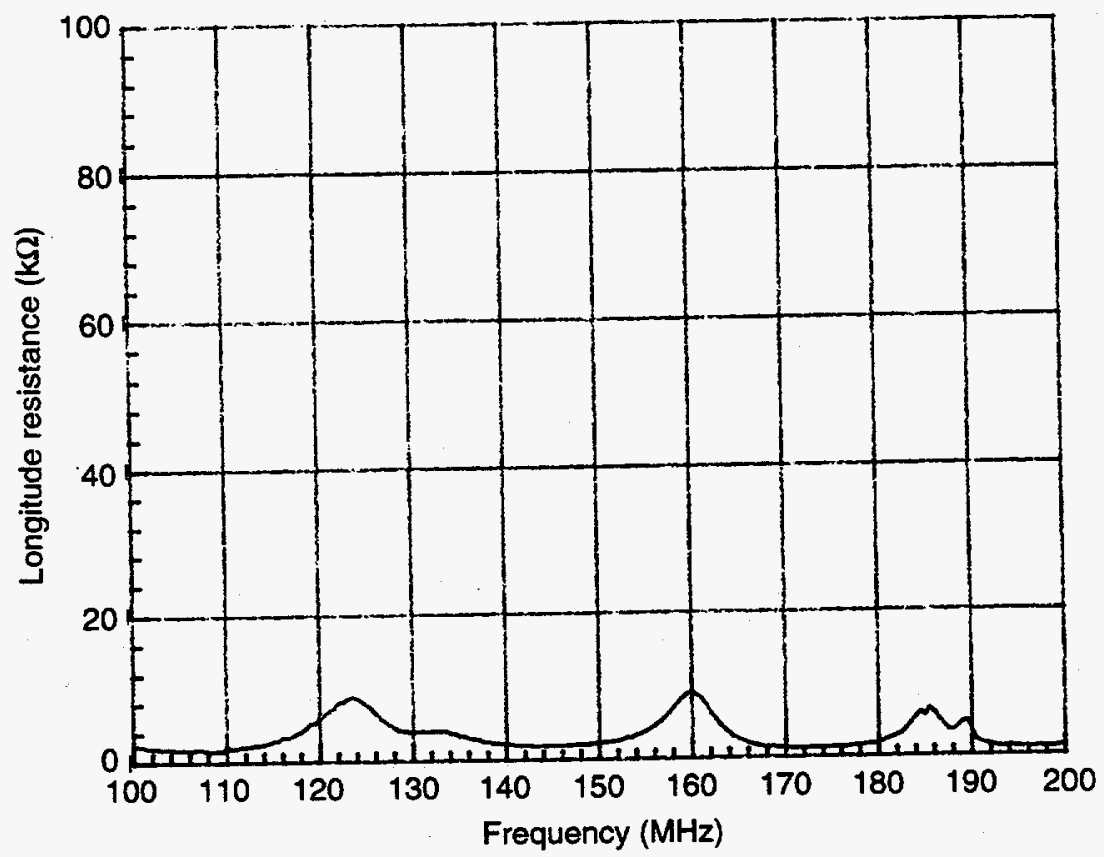

Figure 5. Klcker magnet longitudinal resistive impedance, 100-200 MHz.

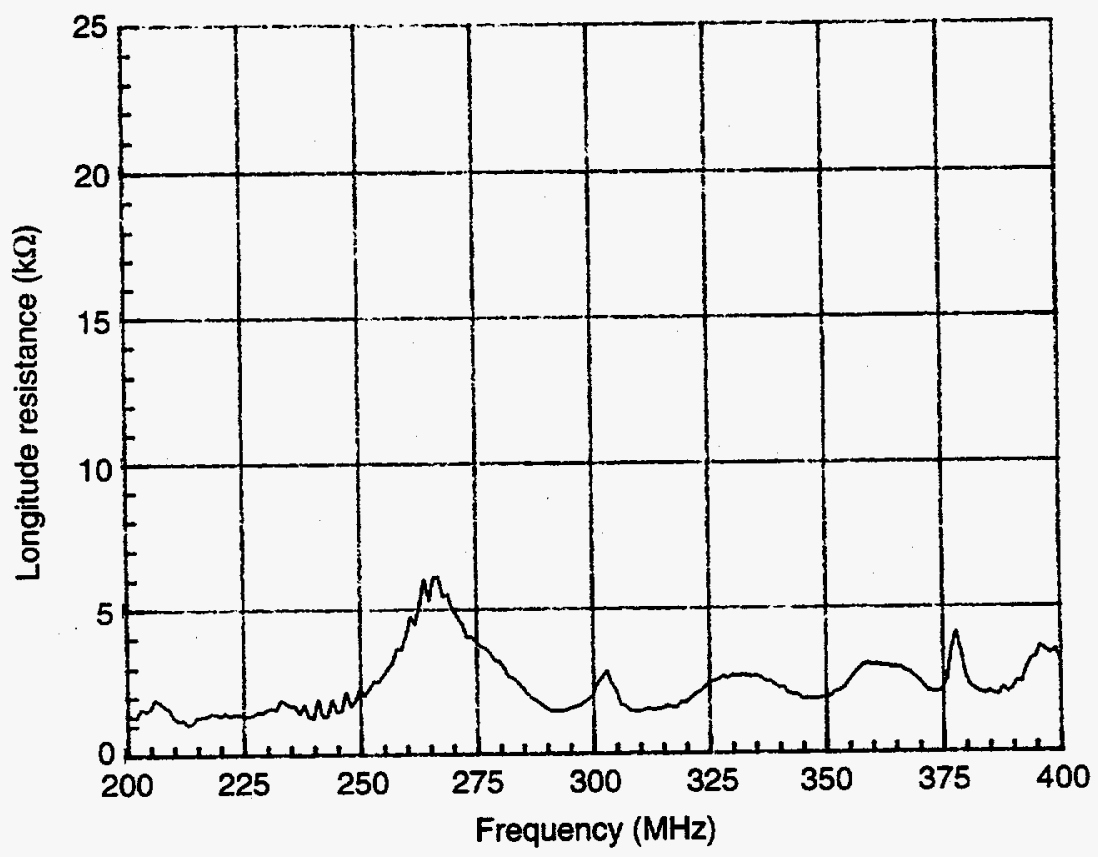

Figure 6. Kicker magnet longitudinal resistive impedance, 200-400 MHz. 


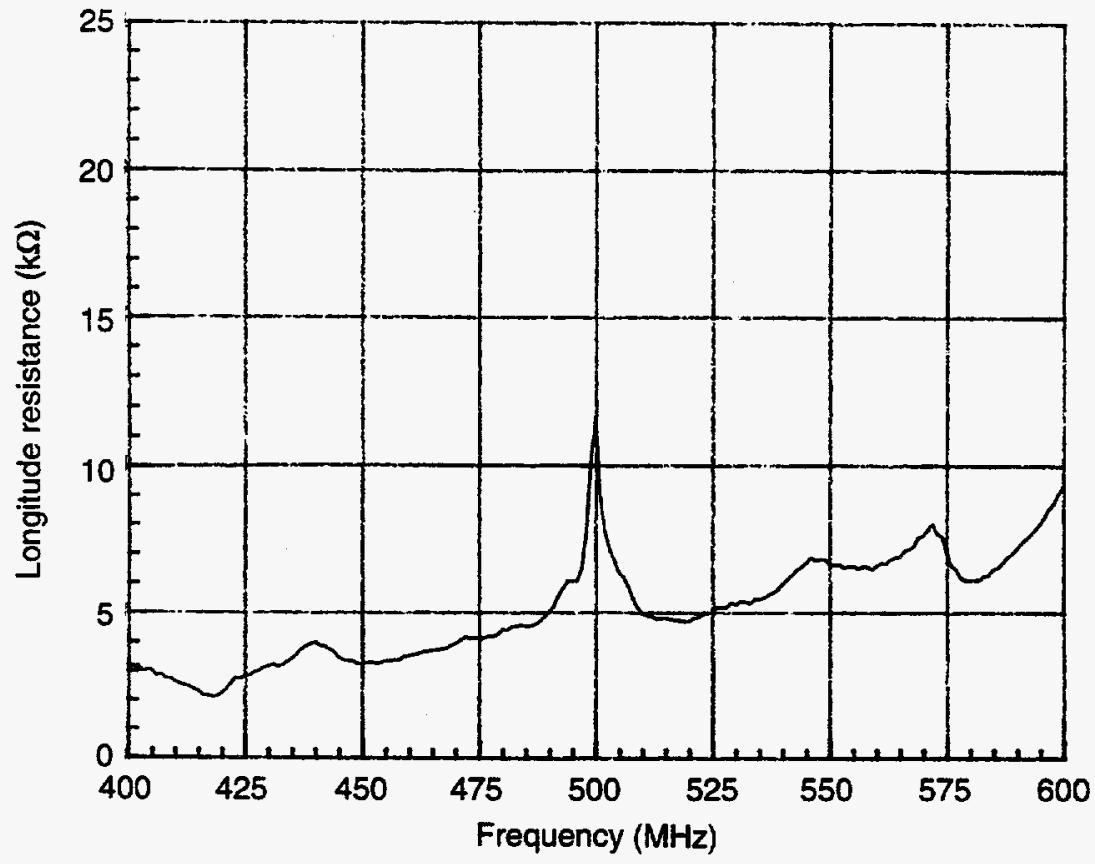

Figure 7. Kicker magnet longitudinal resistive impedance, 400-600 $\mathrm{MHz}$.

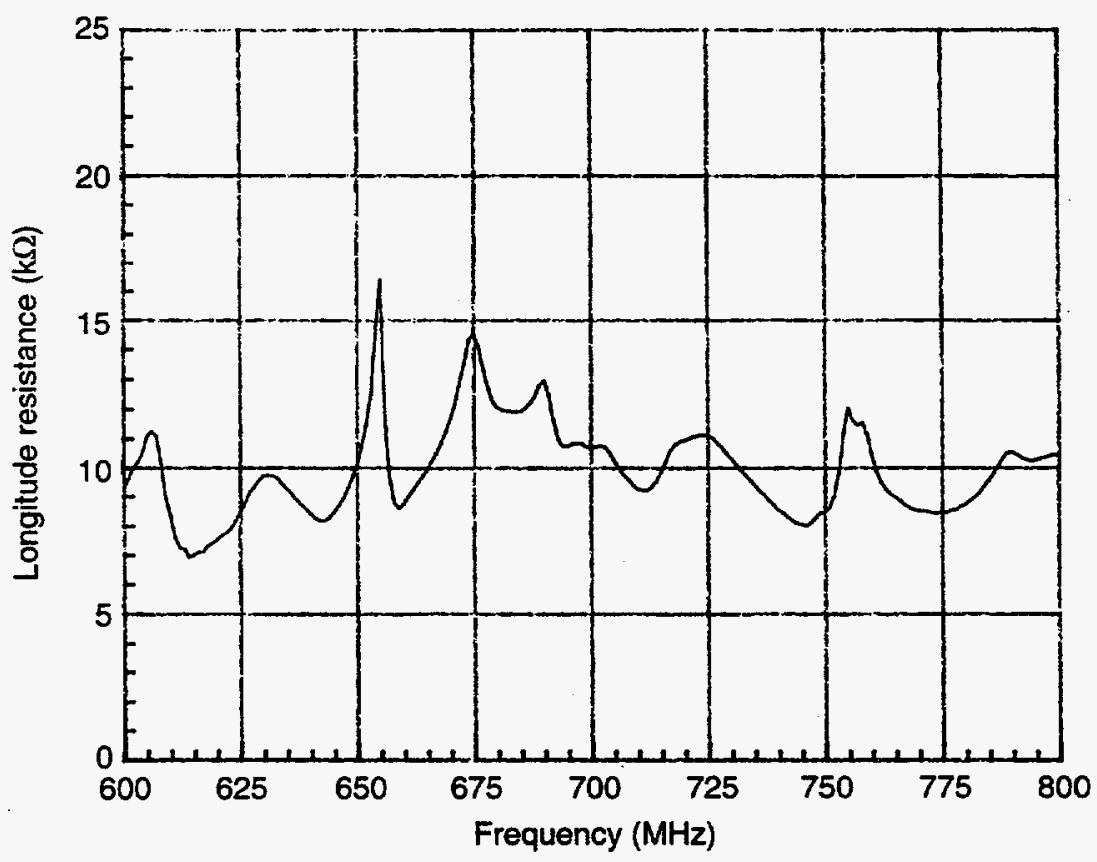

Figure 8. Kicker magnet longitudinal resistive Impedance, 600-800 $\mathrm{MHz}$. 


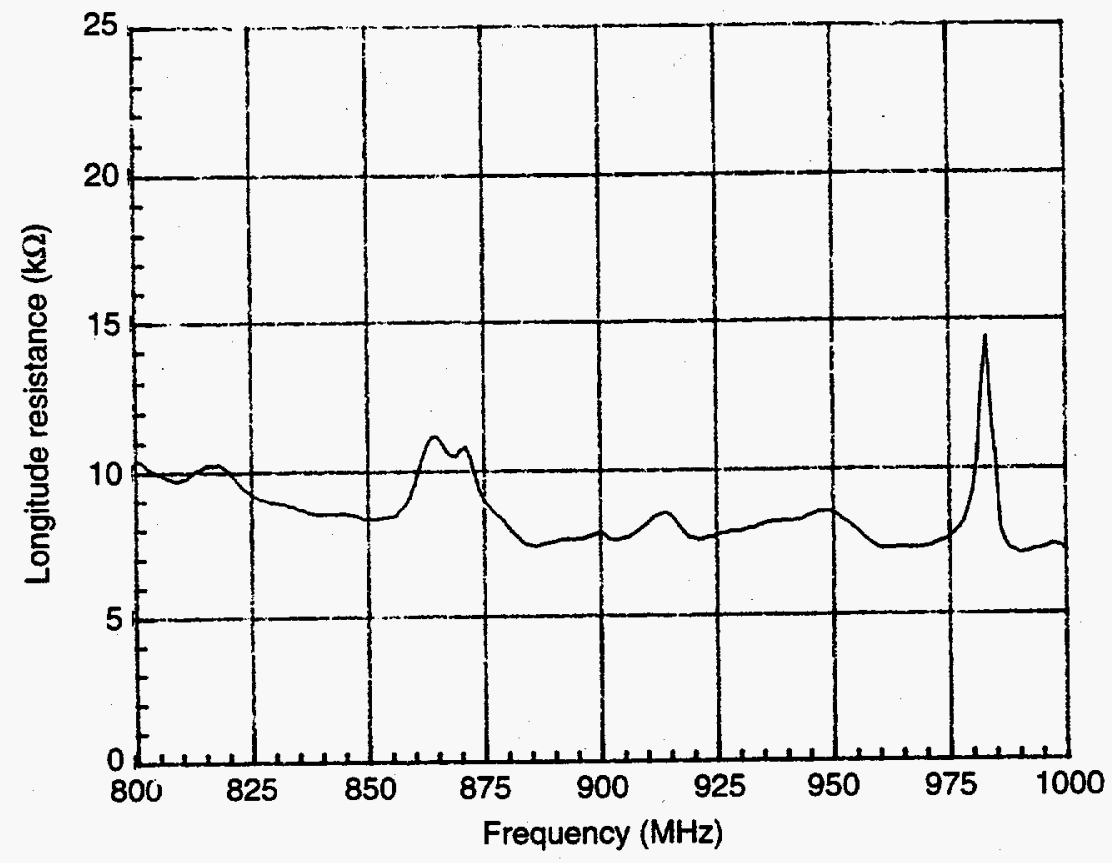

Flgure 9. Klcker magnet longltudinal resistlve impedance, 800-1000 $\mathrm{MHz}$.

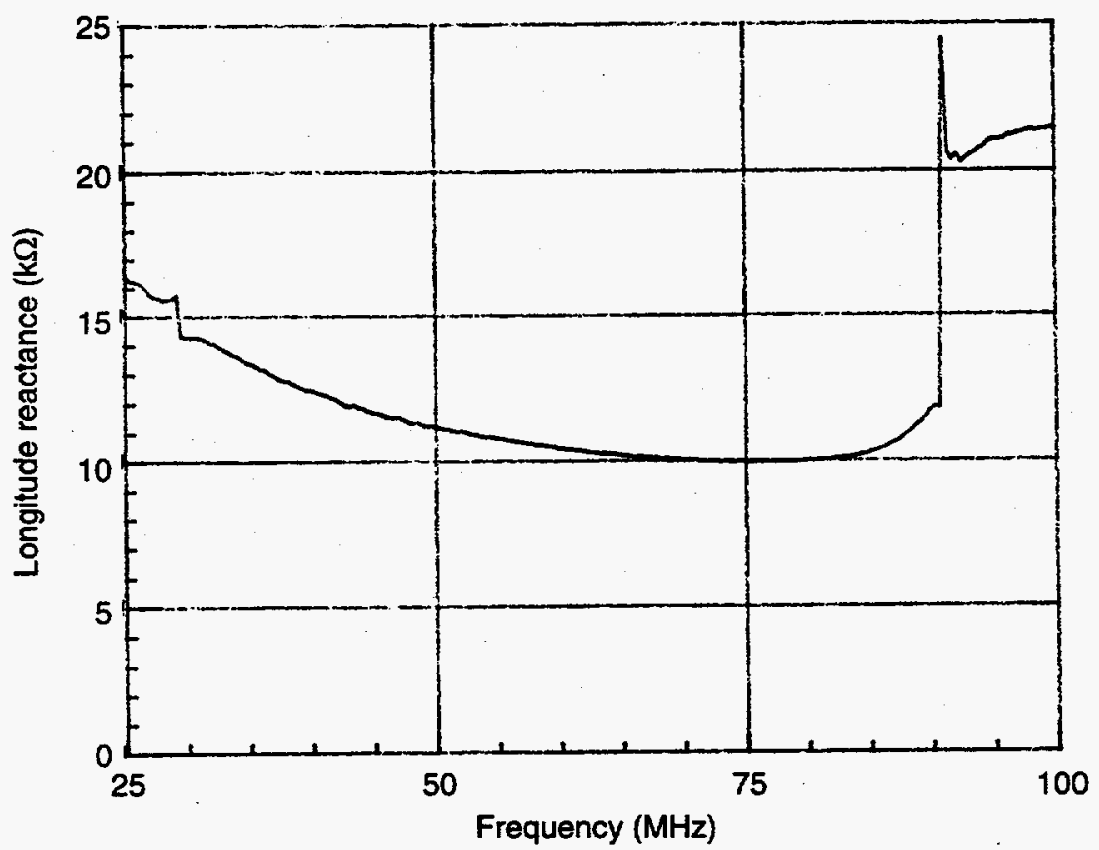

Figure 10. Kicker magnet longitudinal reactive Impedance, 25-100 MHz. 


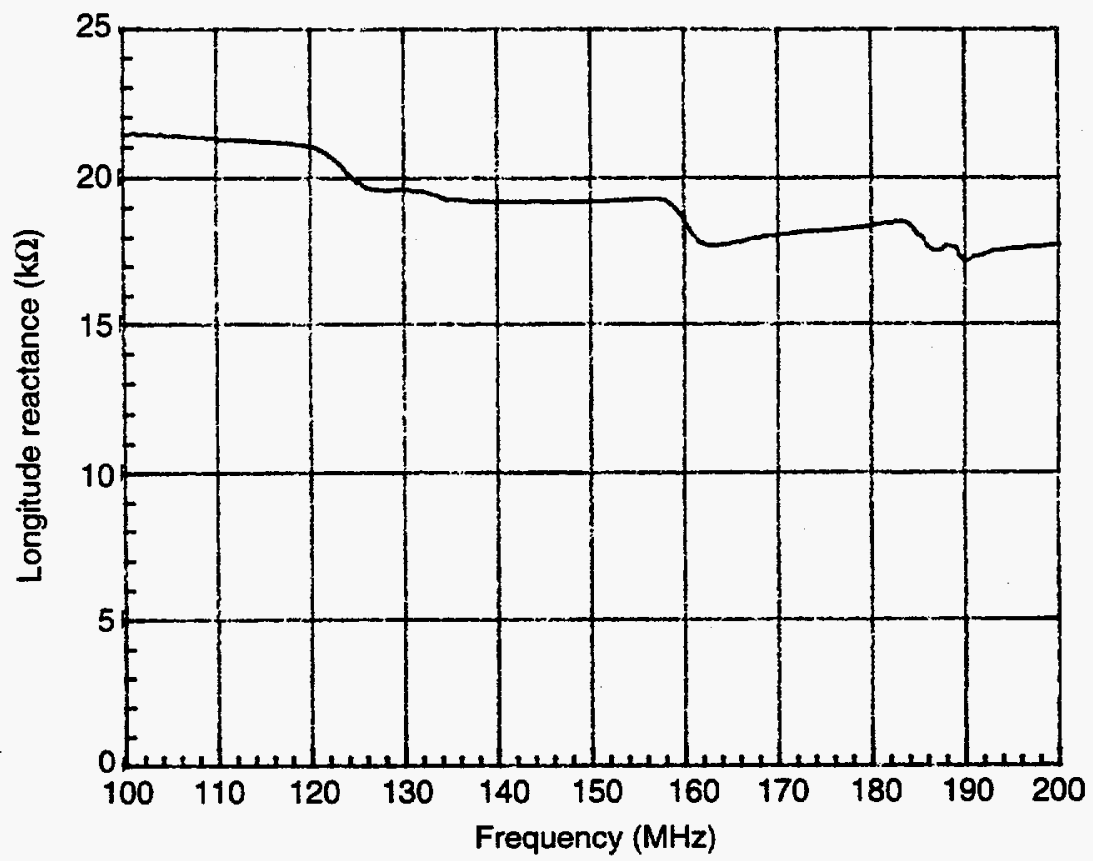

Figure 11. Kicker magnet longitudinal reactive impedance, 100-200 MHz.

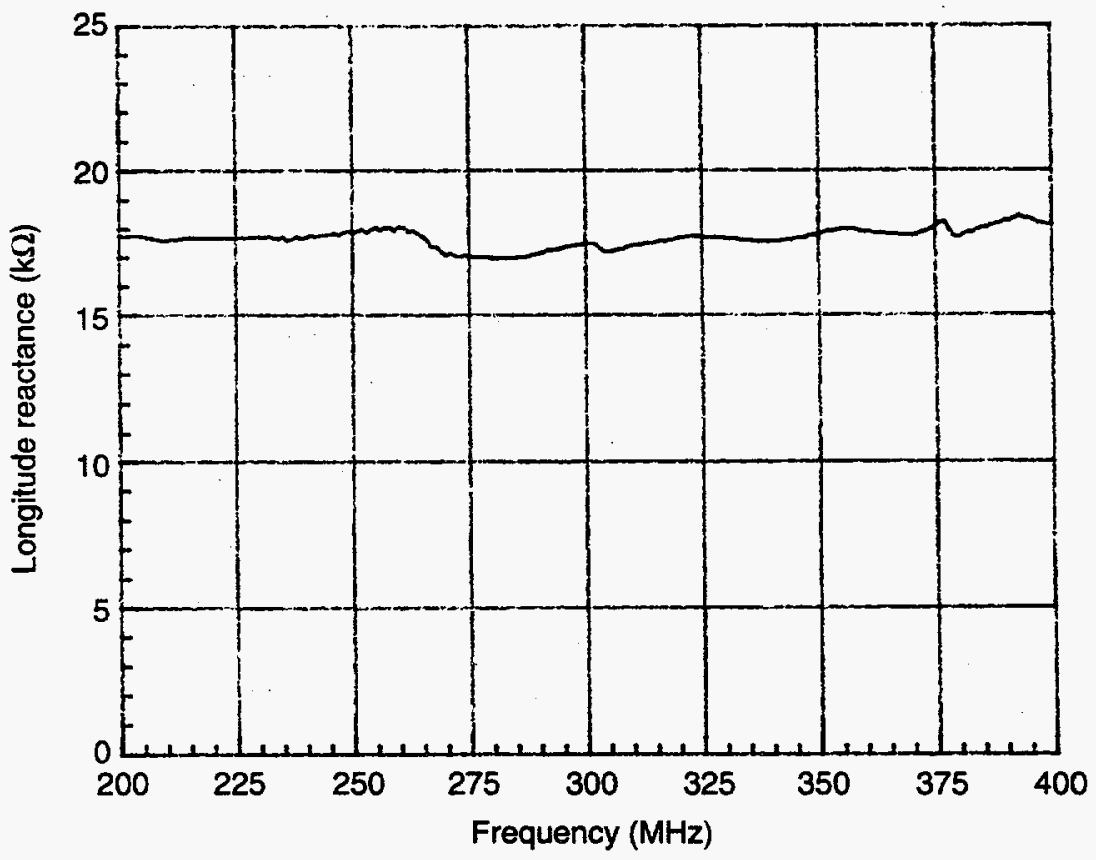

Figure 12. Kicker magnet longitudinal reactive impedance, $200-400 \mathrm{MHz}$. 


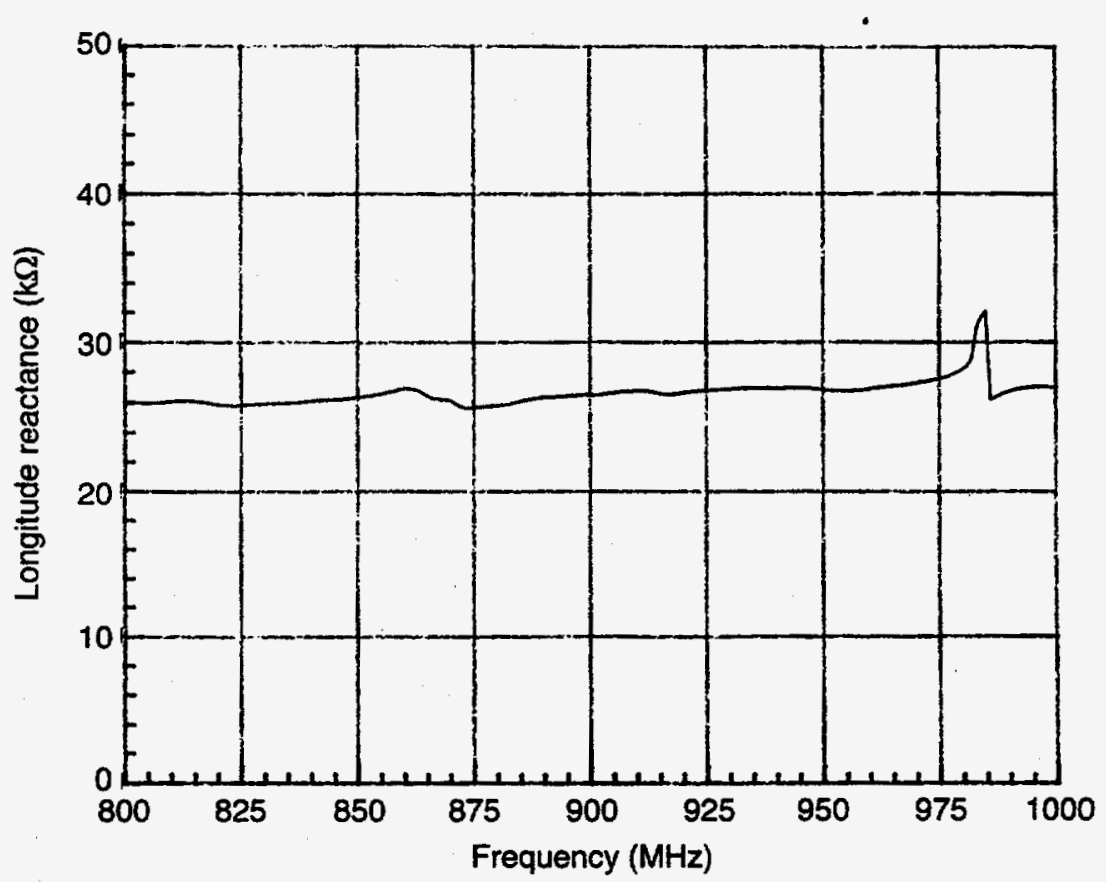

Figure 15. Kicker magnet longltudinal reactive impedance, 800-1000 $\mathrm{MHz}$.

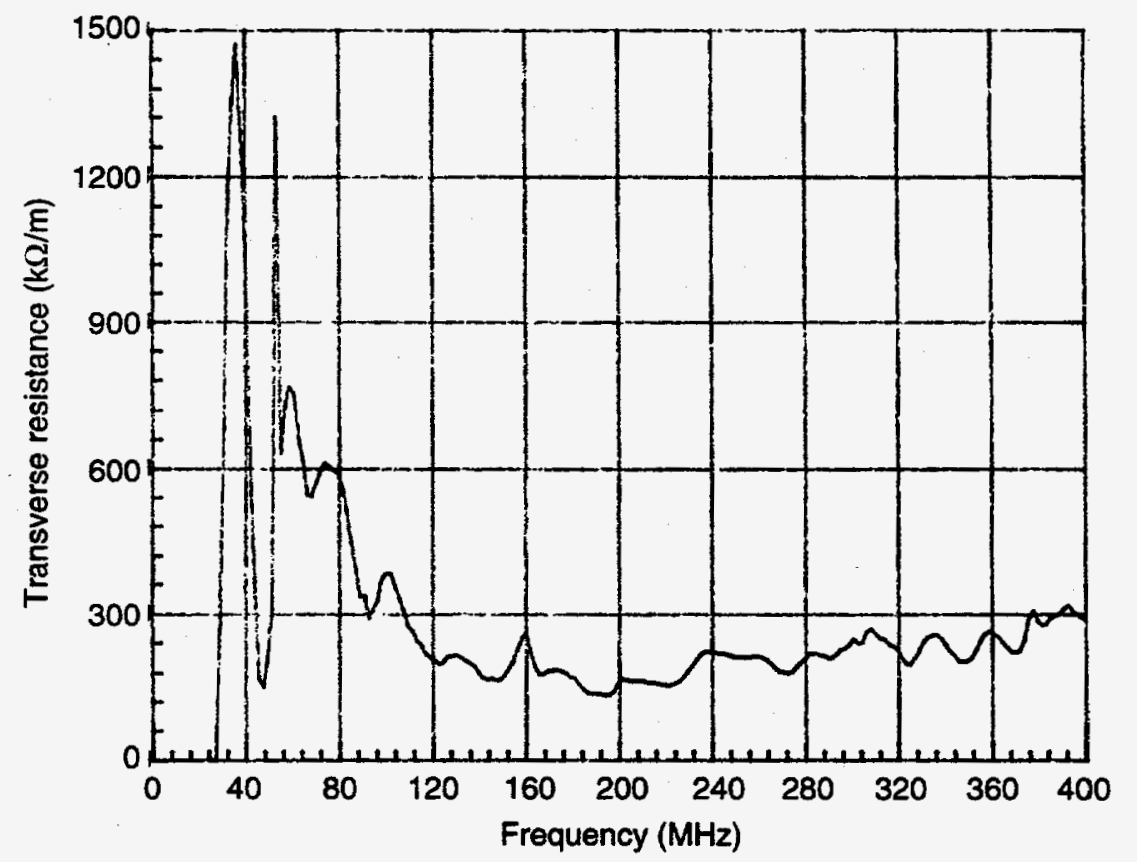

Figure 16. Kicker magnet transverse resistive impedance, $25-400 \mathrm{MHz}$. 


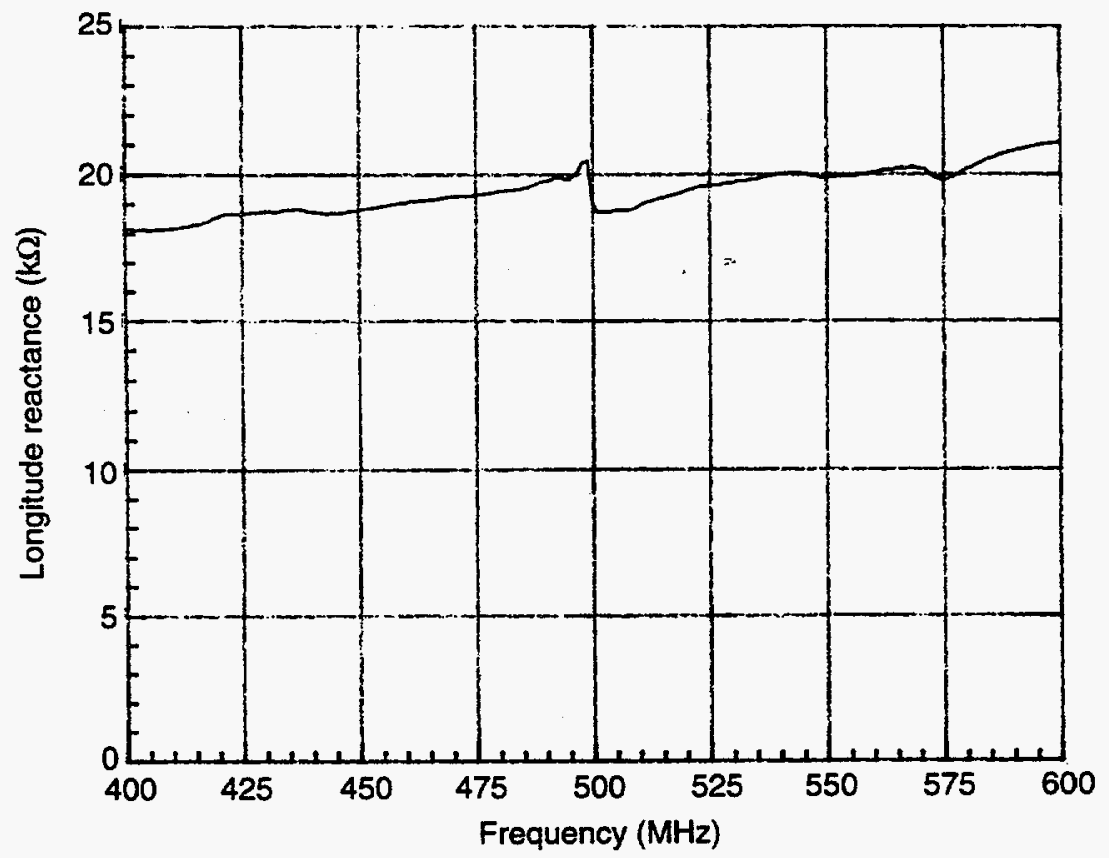

Figure 13. Klcker magnet longitudinal reactive Impedance, 400-600 $\mathrm{MHz}$.

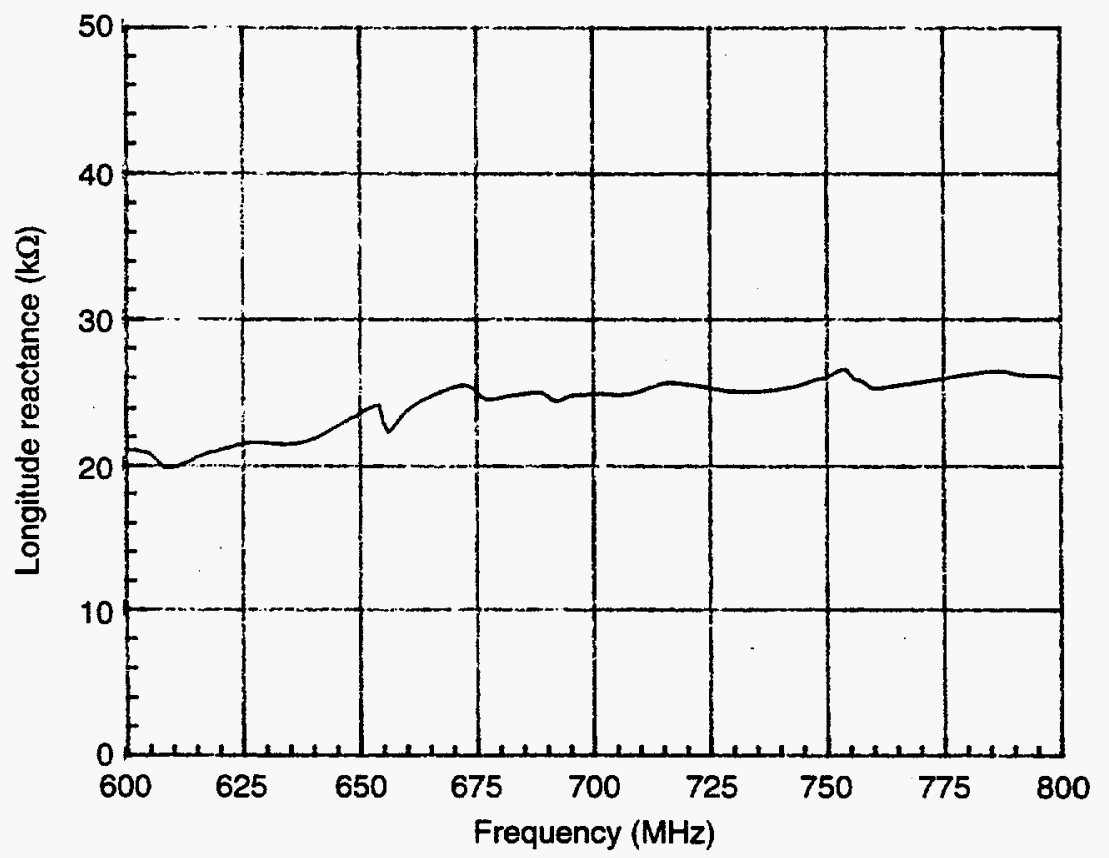

Figure 14. Kicker magnet longitudinal reactive impedance, 600-800 MHz. 


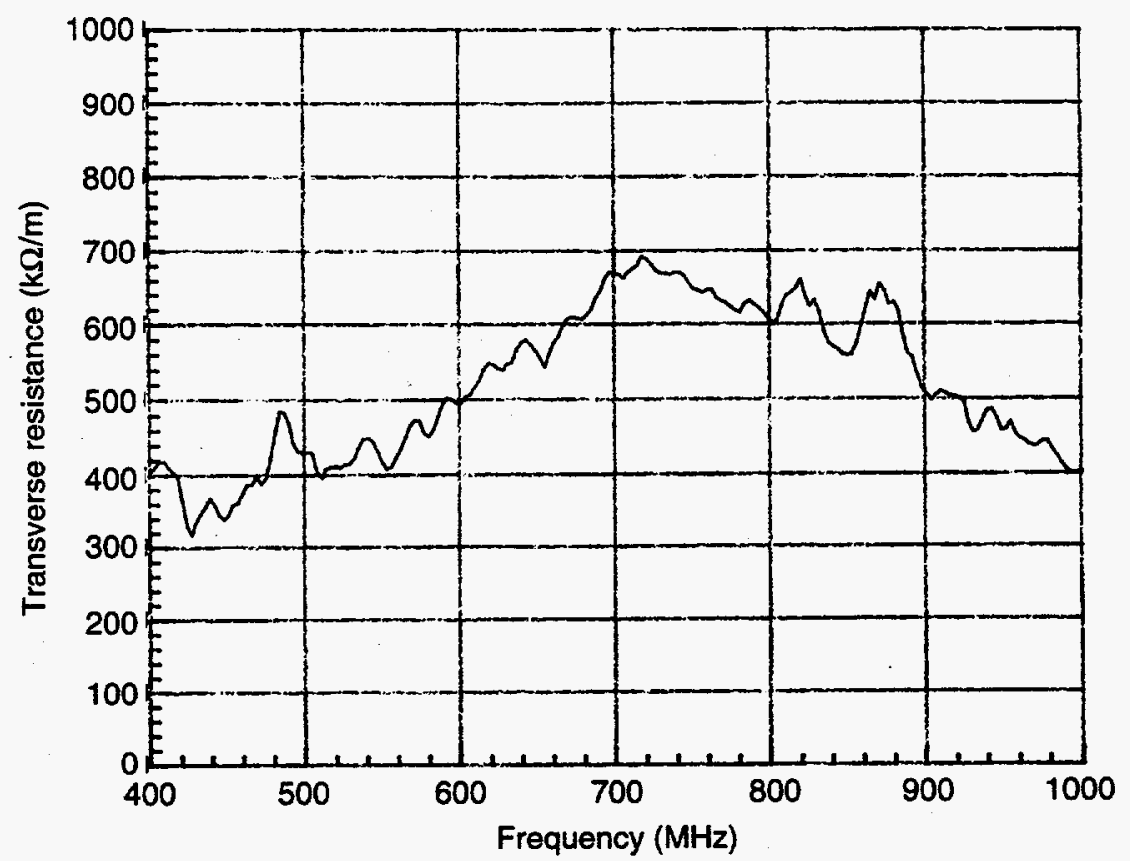

Figure 17. Kicker magnet transverse resistlve impedance, 400-1000 $\mathrm{MHz}$.

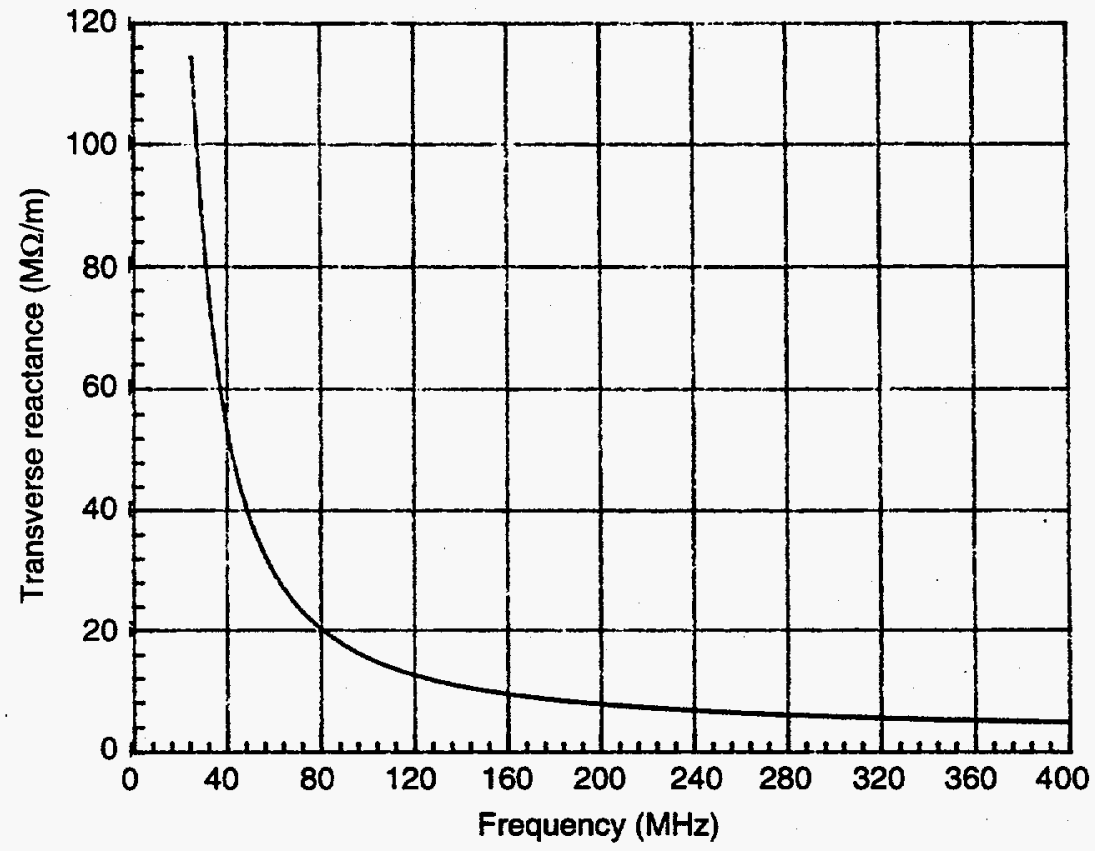

Figure 18. Kicker magnet transverse reactive Impedance, 25-400 MHz. 


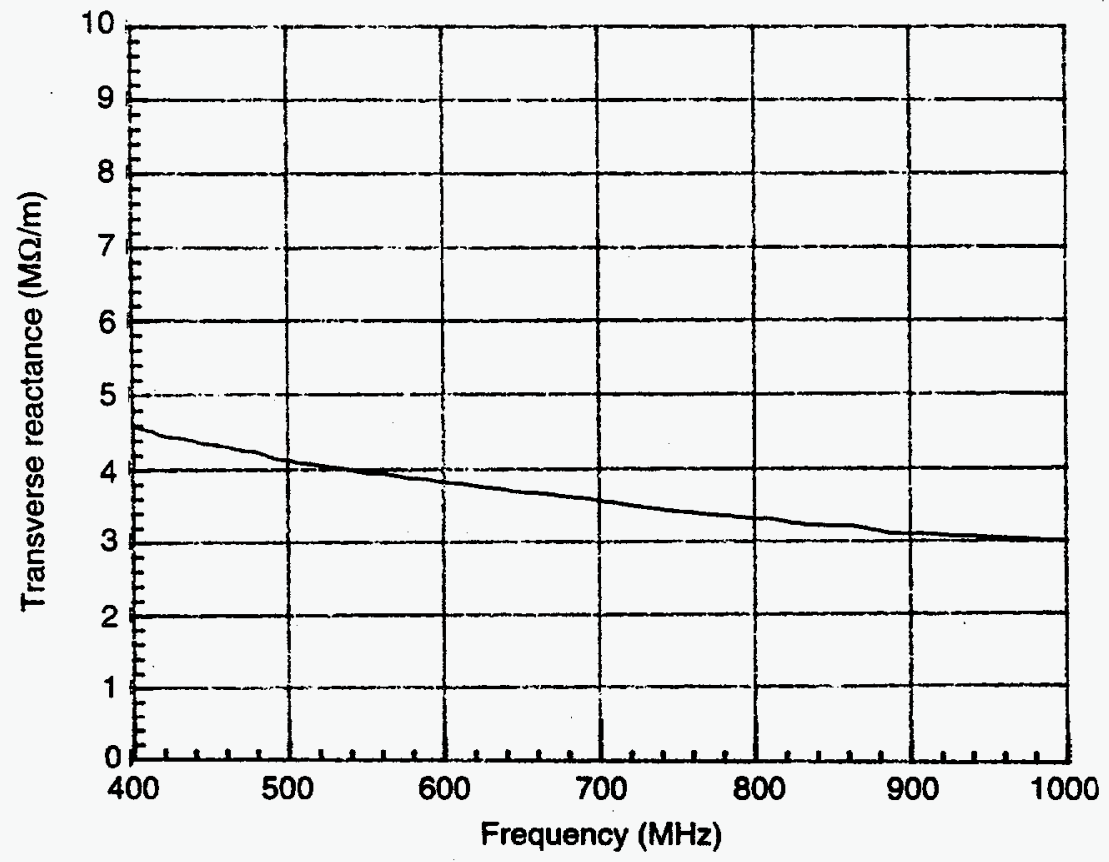

Figure 19. Kicker magnet transverse reactive impedance, 400-1000 $\mathrm{MHz}$. 


\section{REFERENCES}

1. D. Anderson and L. Schneider, "Design and Preliminary Testing of the LEB Extraction Kicker Magnet at the SSC," Proc. of 1993 Particle Accelerator Conference, Vol. 2, p. 1354.

2. L.S. Walling, D.E. McMurry, D.V. Neuffer, and H.A. Thiessen, "Transmission-Line Impedance Measurements for an Advanced Hadron Facility," Nucl. Instr. and Meth. A281 (1989) 433.

3. L.S. Walling, P. Allison, M. Burns, D.J. Liska, D.E. McMurry, and A. H. Shapiro, "Transverse Impedance Measurements of Prototype Cavities for a Dual-Axis Radiographic Hydrotest (DARHT) Facility," 1991 IEEE PAC, San Francisco, CA. May 1991.

4. L. Walling, P. Allison, D.E. McMurry, and A.H. Shapiro, "Transverse Coupling Impedance Measurement Studies of Low- $Q$ Cavities," 1990 Linear Accelerator Conference, Albuquerque, NM, September 1990. 